\title{
关于 VR 安全教育培训系统的设计研究
}

何泽龙 吴奇刘必勇 张良星 姚信

中国核工业二三建设有限公司，北京 101300

[摘要]文章对 VR 安全教育培训系统进行分析, 首先阐述其应用的现实意义, 然后制定该系统的设计方案, 以核电施工为例, 通过 VR 技术对核电施工环境进行模拟, 使新员工能够在逼真的情景下快速熟悉核电施工环境, 减少因不熟悉环境而引发安全 事故。实践表明，通过该系统的应用使课题目标顺利完成，为建筑施工培训提供新的教育方案。

[关键词]VR 安全教育培训系统; 系统设计; 设计方案

DOI: $10.33142 /$ aem.v1i3.961

中图分类号: TU712.4

文献标识码：A

\section{Design and Research on VR Safety Education and Training System}

HE Zelong, WU Qi, LIU Biyong, ZHANG Liangxing, YAO Xin

China Nuclear Industry No.23 Construction Co., Ltd., Beijing, 101300, China

\begin{abstract}
This paper analyzes the VR security education and training system, firstly expounds the practical significance of its application, and then formulates the design scheme of the system. Taking nuclear power construction as an example, the VR technology is used to simulate the nuclear power construction environment, so that new employees can quickly familiarize yourself with the nuclear power construction environment under realistic scenarios, and reduce safety accidents caused by unfamiliar environment. Practice shows that the application of the system enables the successful completion of the project objectives and provides a new educational program for construction training.
\end{abstract}

Keywords: VR security education and training system; system design; scheme design

引言

在科技飞速发展背景下, VR 作为一种新型计算机图形图像技术, 可营造出与现场相同的真实模拟环境, 通过发挥 视觉、触觉等多种形式实现高端人机交互, 在工程、教育、航天等多个方面广泛应用。本文利用该系统对核电施工环 境进行模拟，在此基础上开展安全教育培训工作，以此提高员工素质与技能水平。

\section{VR 安全教育培训系统的实践意义}

1.1 避免培训过程产生意外

VR 技术应用可使训练者远离危险区进行操作, 并获得相应的操作活动, 例如, 在虚拟化火灾场景中, 如若学员处 于站立姿势, 则会触发该场景中某项系统, 出现吸入过多毒气而死亡的场景; 如若学员处于下蹲姿势, 则会解除该系 统, 从而通过训练任务。在训练过程中, VR 技术可对真实的火灾场景进行模拟, 学员无需真正处于火灾之中, 便可掌 握相应的操作技术和方法, 有效避免培训过程中产生意外。

\section{2 高度还原真实场景}

VR 培训具有高度还原真实场景的作用，可使学员在虚拟场景中形成真实情景的意识。目前，市场中应用较多的 VR 硬件可完成视、听、触等方面的情景模拟。在硬件设备的支持下，学员可达到身临其境的效果，“听” 到施工现场机械 运作的轰鸣声, “看” 到各类工程结构的样式, “摆弄” 情景中含有的物件, 学员能在逼真的场景中直接操作从而获得 更多知识, 积累更多经验 ${ }^{[1]}$ 。

\section{VR 安全教育培训系统的设计与实现}

本文以核电施工为例, 通过 VR 技术对核电施工环境进行模拟, 使新员工能够在逼真的情景下快速熟悉核电施工环 境, 减少因不熟悉环境而引发安全事故。同时, 对核电高风险作业进行梳理, 采用多种技术营造高风险作业模拟场景, 力求通过教育培训的方式，减少违规作业的发生。

\section{1 设计方案}

为了使该方案与施工现场相一致, 5 月 28 日在福清项目组织部召开了核电现场喷涂与勘查交流会议, 在会议上听 取多个部门对该课题的研发意见, 最终确定 4 个系统与 22 子项系统, 在原课题中 18 个子系统的基础上增加 4 个新系 统，具体如下：

事故观影系统: 包括机械伤害、高空坠落, 起重伤害、物体打击等;

事故体验系统: 包括机械伤害、高空坠落, 起重伤害、物体打击与触电等, 其中触电又分为临时用电与端接触电 两种;

隐患排查系统: 针对脚手架、临边孔洞、临时用电、汽车吊、高空作业、消防安全、塔吊等多个方面存在的隐患 进行排查。在此基础上，还新增加了三种场景，分别为动火作业、常用工器具与作业环境隐患排查; 
核岛巡游与逃生系统: 包括核岛巡游与特殊情况下的应急疏散 ${ }^{[2]}$ 。

\section{2 设计内容}

2.2. 1 明确使用规则

参与核电施工培训的人员大多没有接触过虚拟现实设备, 在培训中有些不知所措, 在软件设计时应本着方便易学 的目标, 采用简单明了的使用规则使学者能够尽快上手。为了提高教育培训效果, 在编辑程序运行逻辑时, 采用条件 触发机制, 只有学员在满足既定条件下才可使相应的事件发生, 例如, 在场景中, 当学员进入电梯区后才可看到超载 运行下电梯坠毁的画面，这样做可使学员在虚拟现实中获得震撼，从而了解事故发生的原因。

\section{2 .2 人声提醒与符号提示}

据调查, 视觉占人脑接收信息总量的 $83 \%$, 利用人的视线传递信息最为得当, 在项目场景应用中, 射线触发通过头 盔发出与使用者视线相同的射束, 以此来激发事件, 模拟出 “看” 的效果。例如, 在火灾场景中, 当学员 “看” 到过 载插线板隐患时, 场景中便开始展示火灾蔓延的动画。在场景中, 视觉射束的感应区设置了较为明显的纯色标记, 并 搭配人声提醒, 使学员注视标记所处区域, 当学员未注意到该标记时, 场景不会发生变化, 以此方式引导观察者遵循 预定的设计运行程序。通过以上方式, 可使初次使用 VR 技术进行培训的学员无障碍的接受安全教育, 促进该系统的广 泛应用。

\subsection{3 控制模型面数}

在模型制作过程中，应在既定时间与成本内，使虚拟场景最大限度地还原真实场景，使画面运行更加畅通。对此， 该系统中采用中低精度多边形模型, 在场景方面共计包括 5000 面左右, 在道具模型方面包括 150 面左右, 共计 187 个 定点, 人物模型面数为 600-900 三角面之间, 在节约电脑资源的同时, 达到还原真实场景的目的。在制作之初, 由于 模型中的细节众多, 导致软件出现卡顿情况, 需要对模型进行精简处理, 例如在施工安全网中, 采用带有 ALPHA 通道 的镂空贴图替代以往网状结构, 采用法线贴图模拟机械表面结构, 如翻盖、按钮等, 这些均可在保障场景总体效果的 基础上，使软件运行更加流畅。

\subsection{4 场景模拟与特效制作}

采用 mmity 软件中的天空盒替代 Unity 天空盒, 前者可将照片贴图拼合起来, 形成一个球形的外景插件, 它可对 场景周围的景象进行模拟。在制作过程中, 采用平面软件对拍摄的照片进行处理, 使其与背景相同, 边缘处可与 6 张 天空盒的贴图完美衔接, 且将真实情景的地平线位置与模拟场景中的位置调整一致, 将真实的周围场景还原出来。此 外, 利用 Unity3D 软件还可对水、火、烟雾等特效进行制作, 但如若粒子系统使用过度, 常常会影响软件运行的流畅 度, 因此在该项目中, 火焰特效未全部以粒子束的形式体现出来, 而是采用粒子与火苗帧相结合的方式, 做成动态的 贴图来实现，设计者以烟雾贴图的形式展示烟雾特效，使大量烟雾场景得以顺畅运行 ${ }^{[3]}$ 。

\section{3 系统实现}

2.3.1 现场喷涂与勘察

为了让 VR 体验者能够更加深刻的感受到福清华龙一号的真实场景, 共计进入核电施工现场 11 次, 对 5 号机组外 围勘察 3 次, 对 3、4 号机组外围拍摄一次, 对 5 号机组内部的 189 个房间拍摄 1 次, 共计拍摄 3482 张照片, 摄像 37 部, 采集常用工机具 21 种。

\subsection{2 隐患排查系统}

为了使该系统与施工现场实际情况更加贴合, 使员工在培训中更加清楚的看到日常隐患所在, 对项目部 2016一2018 年的隐患情况进行分类调查与数据分析, 最终将隐患根据发生频率进行划分, 并在项目部许可下, 共计设置 114 项常 见隐患, 主要的排查情况如下: 脚手架 14 项、临边孔洞 9 项、临时用电 10 项、汽车吊 12 项、高空作业 12 项、消防 安全 14 项、动火作业 9 项、常用工器具 12 项与作业环境隐患排查 12 项。

2.3.3 现场喷涂完成保障

为保障在福清项目部期间完成全部喷涂与流程设置, 与杭州虚现科技有限公司讨论后, 完成说词、语言、启动等 界面设置, 以及 22 子项系统流程设置、114 项隐患发生情况与 3 条应急疏散路线的设置。最后, 在福清项目的全力配 合下, 项目施工现场的喷涂与勘查工作顺利完成, 为研发防城港华龙一号 VR 安全教育培训奠定坚实基础, 促进课题计 划的顺利落实。

\section{结束语}

综上所述, 在建筑施工中, 安全与质量同等重要, 为了使新学员在较短的时间内熟悉施工环境与流程, 避免安全 事故的发生, 应积极构建 VR 安全培训教育系统, 借助科技的力量将真实的施工情境模拟出来, 让学员更加高效的学习 安全培训内容, 并对各类情境与安全隐患留下深刻印象。

\section{[参考文献]}

[1] 吴学政.VR（虚拟现实）技术在大学生安全教育中的应用研究 [J].中国新通信, 2018,8 (20): 4 .

[2] 黄超, 田丰,褚灵伟。沉浸式 VR 在教育培训领域中的应用综述 [J].电声技术, 2017,4(11): 6.

[3] 沈超. 虚拟现实技术在建筑施工安全教育领域的应用方法探究一以武汉杨泗港长江大桥安全教育体验馆项目为例 $[\mathrm{J}]$. 赤峰学院学报, 2018, 12(6): 8 .

作者简介: 何泽龙 (1986-), 工程师。 